\title{
PROGRAMMABLE SECOND-GENERATION CURRENT-CONVEYOR WITH VARIABLE CURRENT GAIN
}

\author{
MUHAMMAD TAHER ABUELMA'ATTI, ABDULRAHMAN KHALAF \\ AL-ALI AND ABDULRAFEEQ ABDULSHAKOOR
}

King Fahd University of Petroleum and Minerals, Box 203, Dhahran 31261, Saudi Arabia

(Received August 14, 1994; in final form September 7, 1994)

A new programmable second-generation current-conveyor is proposed. The proposed circuit uses a commercially available second-generation current-conveyor and one operational transconductance amplifier. Simulation results confirming the presented theory are included.

\section{INTRODUCTION}

In a recent publication, Carlosena and Moschytz ${ }^{1}$ proposed four practical circuits for implementing a variable current-gain current-conveyor. Each circuit contains one operational amplifier, one negative second-generation current-conveyor (CCII-), and two resistors. The circuits enjoy constant bandwidth whereas the current-gain is controlled by a single floating resistor. Although, the current gain can be digitally programmed, this requires replacing the floating resistor by a bank of resistors and digital switches.

In the present paper, a new practical implementation for a current-conveyor with digitally programmable current gain is presented. The proposed circuit exploits to advantage the programmability of the operational transconductance amplifier. The proposed circuit is, therefore, easily integrable. Experimental results confirming the analysis are given.

\section{PROPOSED CIRCUIT}

Consider the circuit shown in Fig. 1. The characteristic of an ideal CCII can be described by

$$
\begin{aligned}
\mathrm{I}_{\mathrm{Y}} & =0 \\
\mathrm{~V}_{\mathrm{X}} & =\alpha \mathrm{V}_{\mathrm{Y}} \\
\mathrm{I}_{\mathrm{Z}} & = \pm \beta \mathrm{I}_{\mathrm{X}}
\end{aligned}
$$

where $\alpha$ represents the voltage-gain and $\beta$ represents the current-gain of the CCII. The \pm sign indicates whether the conveyor is a CCII + or a $\mathrm{CCII}-$, respectively. 


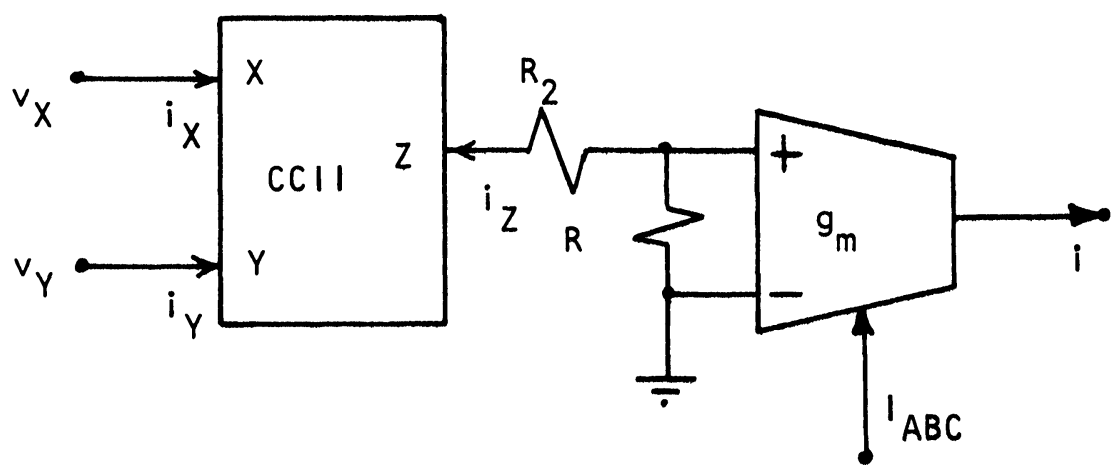

FIGURE 1 Proposed Programmable Current Conveyor

For a conventional CCII the current and the voltage gains are equal to unity, i.e., $\alpha=\beta=1$.

The characteristic of the operational transconductance amplifier (OTA) is assumed ideal with

$\mathrm{i}=\mathrm{g}_{\mathrm{m}}\left(\nu_{+}-\nu_{-}\right)$

where $\mathrm{g}_{\mathrm{m}}$ is the transconductance of the OTA and $\nu_{+}$and $\nu_{-}$are the positive and negative input voltages of the OTA.

Using (1) and (2), routine analysis shows that the characteristics of the proposed circuit can be described by

$\mathrm{I}_{\mathrm{Z}}=\mathrm{g}_{\mathrm{m}} \mathrm{RI}_{\mathrm{X}}$

$\mathrm{I}_{\mathrm{Y}}=0$

$\mathrm{V}_{\mathrm{X}}=\mathrm{V}_{\mathrm{Y}}$

From (3)-(5), one can see that the proposed circuit represents a second-generation current-conveyor with current gain that can be controlled by adjusting $g_{m}$. It is worth mentioning here that $g_{m}$ can be linearly controlled over four decades using the auxiliary bias current $\mathrm{I}_{\mathrm{ABC}}$. If this current is obtained from the output of a digital-to-analog converter (DAC), then $\mathrm{g}_{\mathrm{m}}$, and consequently the current gain, can be digitally programmed using the output of a microprocessor in a microprocessorbased system.

\section{EXPERIMENTAL RESULTS}

The proposed circuit of Fig. 1 was tested using the AD844 as a CCII and the CA3080 OTA. The bias current $\mathrm{I}_{\mathrm{ABC}}$ of the OTA was obtained from the output of a digital-to-analog converter (DAC). The input of the DAC was obtained from a 


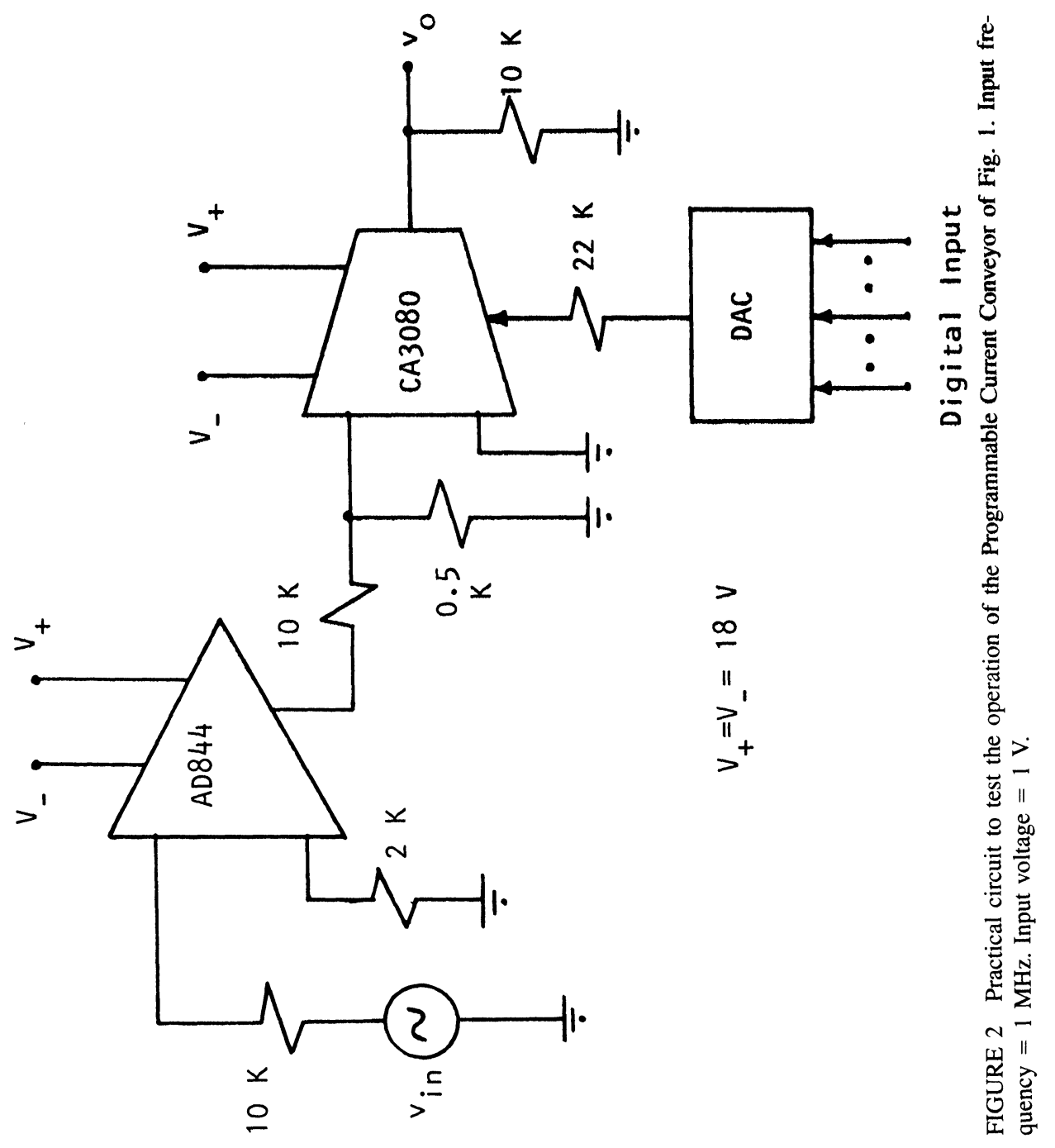


TABLE I

Results obtained from the setup of Fig. 2 Vin $=1 \mathrm{~V}$, frequency $=1 \mathrm{MHz}$

\begin{tabular}{lll}
\hline DAC (input) & $I_{\mathrm{ABC}}(m A)$ & $V_{o}($ volts $)$ \\
\hline 00 & .748 & 1.15 \\
10 & .79 & 1.20 \\
20 & .833 & 1.25 \\
30 & .875 & 1.3 \\
40 & .918 & 1.35 \\
50 & .960 & 1.4 \\
60 & 1.00 & 1.5 \\
70 & 1.04 & 1.6 \\
80 & 1.08 & 1.7 \\
90 & 1.13 & 1.75 \\
A0 & 1.17 & 1.8 \\
B0 & 1.22 & 1.9 \\
C0 & 1.26 & 2.0 \\
D0 & 1.3 & 2.1 \\
E0 & 1.34 & 2.2 \\
F0 & 1.38 & 2.3 \\
FF & 1.39 & 2.3 \\
\hline
\end{tabular}

keyboard. The complete circuit diagram is shown in Fig. 2. The results obtained are shown in Table I. From Table I one can see that the gain of the proposed CCII circuit can be changed from 1.15 to 2.3 by changing the digital input from 00 to FF.

\section{CONCLUSION}

In this paper, a new programmable CCII circuit has been proposed. The circuit enjoys variable current gain that can be digitally programmed. This clears the way to electronic tuning of the current gain, and hence the important parameters of circuits using this programmable CCII as active element.

\section{REFERENCES}

[1] A. Carlosena and G.S. Moschytz, Design of variable-gain current conveyors, IEEE Transactions on Circuits and Systems-I: Fundamental Theory and Applications, Vol. 41, 1994, pp. 79-81. 

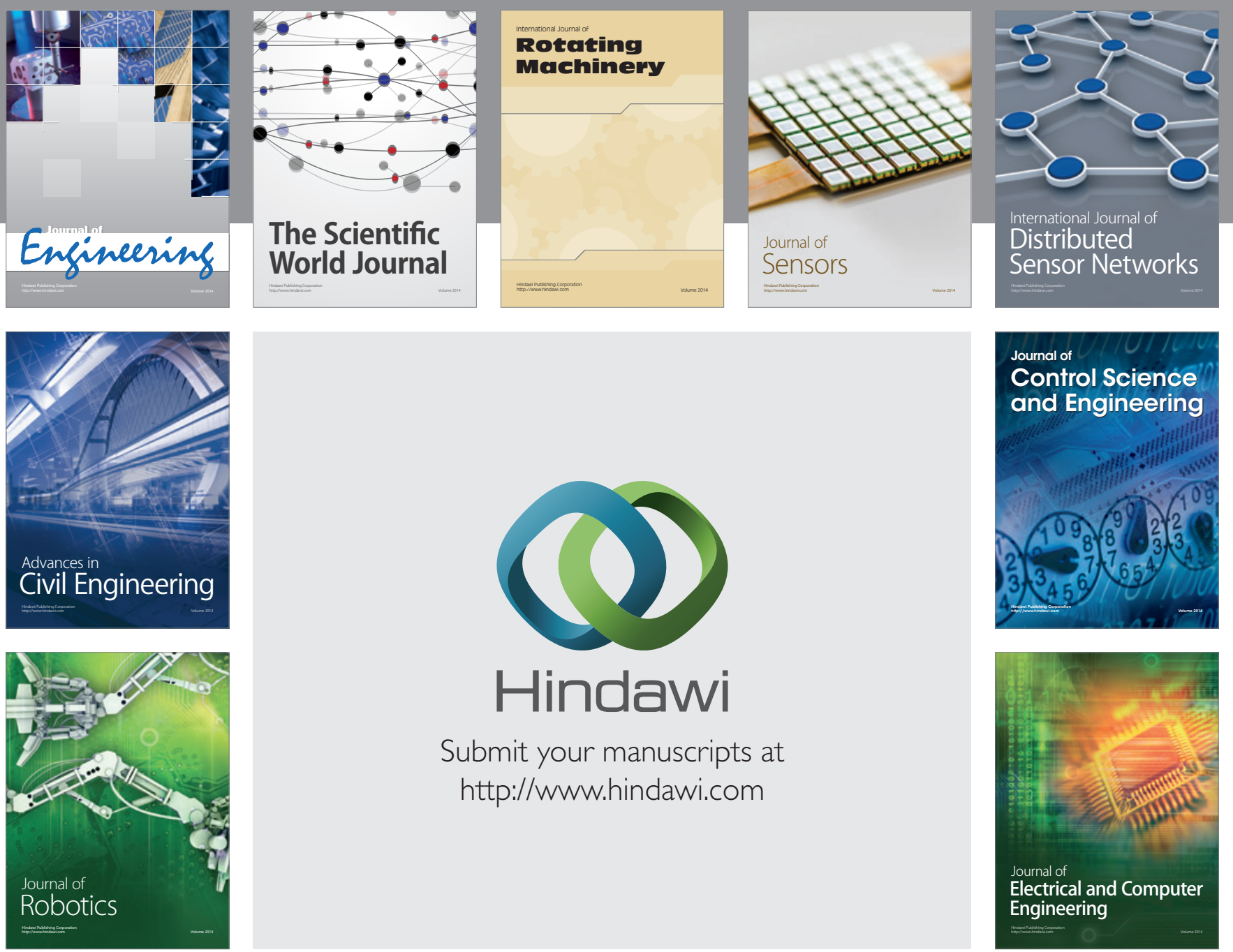

Submit your manuscripts at

http://www.hindawi.com
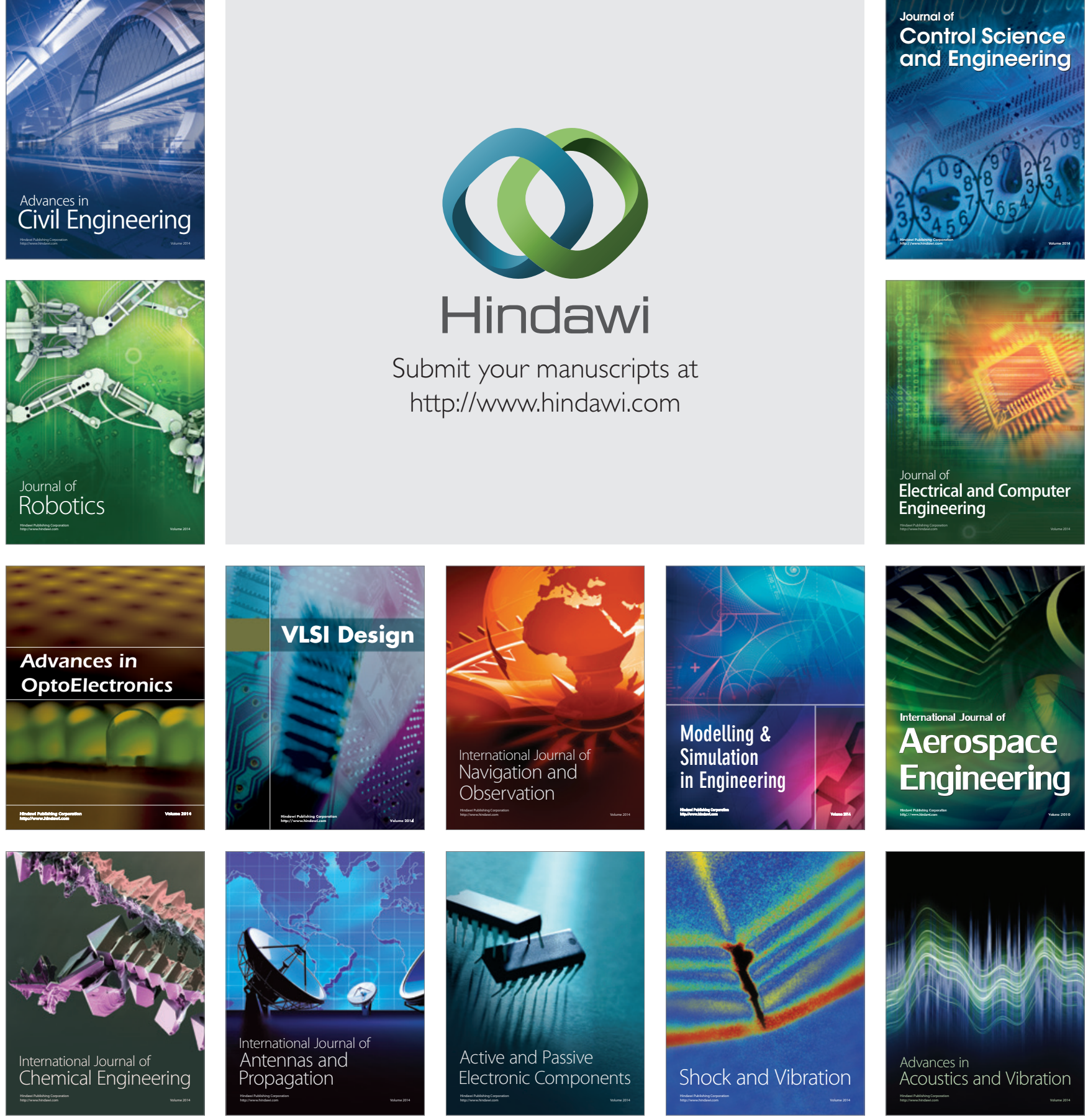